\title{
AS PROVAS NO PROCESSO JUDICIAL SOB A ÓTICA DA EPISTEMOLOGIA
} JURÍDICA

Ana Luiza Barroso Caracas de Castro**

Buscando solucionar uma demanda, investiga-se o contexto fático e probatório apresentado, para que se criem presunções sobre quais seriam as melhores medidas a serem adotadas para atingir a eficaz prestação da tutela jurisdicional. Considera-se que o que garante a segurança jurídica é a dialética e o contraditório dentro dos processos judiciais, a partir do falseamento das teorias existentes, como medida de preservação do devido processo legal e do Estado Democrático de Direito. O objetivo do trabalho é investigar o caráter epistemológico da análise probatória dentro do processo judicial, a partir de vasta pesquisa bibliográfica, investigativa e qualitativa.

Palavras-chave: Provas. Fatos. Compreensão. Contraditório. Dialética.

\section{THE EVIDENCE IN THE JUDICIAL PROCESS FROM THE PERSPECTIVE OF LEGAL EPISTEMOLOGY}

Seeking to solve a demand, the factual and evidential context presented is investigated, in order to create assumptions about what would be the best measures to be adopted to achieve the effective provision of judicial protection. It is considered that what guarantees legal security is the dialectic and the contradictory within the judicial processes, from the falsification of the existing theories, as a measure of preservation of the due legal process and of the Democratic State of Law. The objective of the work is to investigate the epistemological character of the probative analysis in the judicial process, based on a vast bibliographic, investigative and qualitative research.

Keywords: Evidence. Facts. Understanding. Contradictory. Dialectic.

\footnotetext{
* Mestranda em Direito Constitucional pelo Programa de Pós Graduação da Universidade Federal do Ceará e Advogada.

Rev. de Teorias da Justiça, da decisão e da argumentação jurídica | e-ISSN: 2525-9644| Evento Virtual| v. 6 | n. 1 | p. 55-75 | Jan/Jun. 2020
} 


\section{Introdução}

O processo judicial é um procedimento garantido aos cidadãos dentro de um Estado Democrático de Direito para que estes possam exercer a plena eficácia dos seus direitos e também possam dirimir possíveis conflitos advindos das relações entre os grupos que compõem a sociedade. Sendo assim, os instrumentadores do processo visam "conhecer" os fatos apresentados nos autos, por meio da valoração das provas, buscando alcançar a "verdade" sobre determinada demanda, para que assim, possam atingir uma solução mais justa para a demanda das partes envolvidas.

A cognição é limitada devido a própria biologia humana, que não permite a compreensão da realidade da forma com que ela é posta pela natureza. Os seres humanos possuem a capacidade de interpretar todos os elementos que lhe são apresentados, desta feita, os conhecimentos adquiridos nada mais são do que os resultados dessas interpretações, que podem variar de acordo com o ponto de vista adotado por cada indivíduo, a partir das suas percepções em relação a outros conhecimentos predeterminados, como os valores morais e questões inerentes ao seu senso comum. À vista disso, o processo cognitivo realizado a partir da valoração dos elementos probatórios também é limitado.

As provas podem ser conceituadas como o conjunto de elementos utilizados para solucionar uma demanda. Visto que a verdade absoluta sobre determinada questão não pode ser alcançada, busca-se investigar o contexto fático apresentado, com a finalidade de se aproximar de uma crença de veracidade, para que, dessa maneira, se criem presunções sobre quais seriam as melhores medidas a serem adotadas para atingir a justa prestação da tutela jurisdicional. Contudo, essas presunções precisam ser constantemente refutadas por meio dos mecanismos linguísticos que compõem o contraditório e a ampla defesa, para que assim a segurança jurídica possa ser garantida.

Diante disso, o objetivo específico do presente trabalho é investigar o juízo fático criado a partir da análise probatória e seu caráter epistemológico no processo. Para elaboração deste trabalho, foi realizada vasta pesquisa bibliográfica por meio de diversos periódicos em revistas, doutrinas, trabalhos científicos, dentre outros mais, com a citação de obras nacionais e estrangeiras. Este artigo se baseou, especialmente, nos ensinamentos preconizados pela Epistemologia Jurídica, adentrando, notadamente, no estudo da teoria do conhecimento e na teoria da prova, a partir da análise da importância dos fatos, da percepção acerca das presunções,

Rev. de Teorias da Justiça, da decisão e da argumentação jurídica | e-ISSN: 2525-9644| Evento Virtual| v. 6 | n. 1 | p. $55-75$ | Jan/Jun. 2020 
e dos mecanismos de verificação destas por meio do procedimento linguístico argumentativo adotado pela dialética dentro do contraditório processual. Ademais, a discussão se divide em quatro questionamentos principais, quais sejam: É possível alcançar a verdade por meio da análise das provas?; qual a relevância dos fatos para que se atinja a tutela jurisdicional?; qual o papel das presunções?; e, por fim, como as provas podem ser trabalhadas pelos operadores do Direito?

2 É possível alcançar a verdade por meio da análise das provas?

Não há como delimitar especificamente o que pode ser considerado como prova dentro de um processo, diante disso, Hugo Machado Segundo e Raquel Machado (2014, p. 1246) afirmam que "prova é uma palavra plurissignificativa", conceituando as provas, de maneira geral, como todos os elementos utilizados para fundamentar uma decisão dentro do trâmite processual. Ressalta-se também a visão de Michele Taruffo (2009) que afirma que a prova é qualquer elemento que possa vir a ser usado para estabelecer a verdade acerca dos fatos de uma causa.

Destaca-se que, dentre esses elementos utilizados para fundamentar uma decisão, que no caso, caracterizam as provas processuais, há também as percepções subjetivas de quem exerce a função de manuseio dessas provas, ou transmitindo-as, ou valorando-as. Por isso, todos os elementos que constituem um processo podem ser utilizados como meio de prova para a adoção de determinada solução; e essa solução depende de como os operadores do Direito irão interpretar esses elementos, por meio dos mecanismos linguísticos da argumentação e do embate dialético entre eles, em consonância com a valoração normativa dessas provas, respeitando as estipulações legais apresentadas por cada área do Direito.

Contudo, a dificuldade em definir especificamente o que poderia ser considerado como prova não acarreta nenhum prejuízo ao processo cognitivo realizado em uma demanda judicial, na realidade, a dificuldade está em como essas provas seriam trabalhadas pelo poder judiciário e quais as particularidades que seriam aplicadas a elas, respeitando-se os limites cognitivos para o alcance da verdade e de como cada área jurídica trabalha a ideia das provas. Michelle Taruffo (2009) defende que as provas, enquanto elemento integrante da fundamentação judicial, seriam como mandamentos de otimização, que são caracterizados segundo a visão de Robert Alexy $(2015$, p. 90$)$ "por poderem ser satisfeitos em graus variados e pelo fato de que a medida devida 
de sua satisfação não depende somente das possibilidades fáticas, mas também das possibilidades jurídicas".

Importante destacar a ideia de Michelle Taruffo (2009), em que as provas buscam a verdade ou algo próximo a ela, para que se possa alcançar uma solução "justa" para os conflitos sociais que se apresentam dentro de uma determinada demanda. Sendo assim, a criação de uma teoria acerca da verdade é essencial para alcançar a justiça, qualquer que seja o critério de justiça. Para o autor, a melhor forma de se chegar a uma ideia de verdade seria conhecer o fato envolvido na análise, sendo indispensável a aplicação desse critério. Por isso, a melhor forma de se atingir a justiça, adotando sua concepção na forma de pacificação de um conflito, é se aproximando da realidade dos fatos. Percebe-se que a relação entre as provas e a verdade é direta e evidente, visto que é por meio desses elementos que se cria uma "crença de veracidade" dentro do processo, por meio da construção cognitiva realizada a partir dos fatos apresentados, criando uma espécie de "presunção" que será considerada para se atingir uma melhor solução para a demanda.

Antes de adentrar a discussão sobre a relevância dos fatos para a valoração das provas judiciais, é importante adentrar ao problema da teoria do conhecimento que dificulta o alcance da verdade sobre os fatos. Os seres humanos, ao perceberem a realidade posta por meio de seus sentidos cognitivos, possuem uma compreensão limitada e acabam baseando os seus conhecimentos por meio das interpretações de suas experiências cotidianas e o estudo de teorias a respeito dos assuntos que abrangem suas áreas de interesse.

Enrique R. Aftalión, José Vilanova e Julio Raffo (2004) explicam que os seres humanos buscam o conhecimento na tentativa de explicar a realidade, como um enfoque existencial, com o intermédio de sua capacidade crítica para analisar os elementos da vida cotidiana. Nesta seara, prelecionam que os conhecimentos são adquiridos reflexivamente por meio da linguagem e não se desvinculam de outros conhecimentos implícitos pré-determinados tanto pela evolução biológica da espécie humana, quando por opiniões valorativas e morais adquiridas através das interações dos grupos sociais, contudo, os indivíduos devem buscar superar esse conhecimento advindo de habilidades comuns, investindo em um "saber practognótico", buscando uma ideia mais próxima da verdade. Para Gaston Bachelard (1996, p. 18-19), o conhecimento deve ser visto como um fenômeno peculiar de consciência que se 
fundamenta na autorreflexão constante sobre experiências trazidas pela realidade prática ou teórica, afirmando:

O conhecimento adquirido pelo esforço científico pode declinar. A pergunta abstrata e franca se desgasta: a resposta concreta fica. A partir daí, a atividade espiritual se inverte e se bloqueia. Um obstáculo epistemológico se incrusta no conhecimento não questionado. Hábitos intelectuais que foram úteis e sadios podem, com o tempo, entravar a pesquisa.

Thomas Kuhn (2005) preconiza uma estrutura revolucionária, demonstrando a percepção por meio de paradigmas para o processo de aquisição do conhecimento científico. Os paradigmas são resultados de realizações científicas que proporcionam um grau de fundamentação seguro para determinado conhecimento adquirido pela percepção humana. Esses paradigmas não são adotados como corretos, mas sim como um parâmetro que condiz melhor com a realidade até então estudada pelos pesquisadores; podendo, desta feita, serem superados por outros paradigmas que venham a surgir e se adequem melhor com a sociedade e com os resultados adquiridos mediante o confronto entre teorias científicas. A superação de paradigmas enseja uma revolução científica. Em contrapartida, a teoria criada por Thomas Kuhn sofre críticas pertinentes, justificadas pela ideia de que, como os paradigmas sempre poderão ser superados por meios revolucionários, então as teorias sempre estarão abarcadas pela visão relativista, explicada por Paul Feyerabend (2011) sob o argumento de que todos os conhecimentos adquiridos pelos seres humanos, inclusive o senso comum, a magia, a religião, dentre outros, podem ser considerados científicos, visto que todos esses conhecimentos são relativos, podendo ser superados.

De fato, existem limitações à cognição humana e isso impossibilita o nosso conhecimento absoluto sobre a realidade. Entretanto, não se quer, neste trabalho, adotar uma concepção relativista, em que toda e qualquer teoria poderia ser considerada verdadeira, sem que se possa alcançar uma "crença de verdade" sobre os fatos. Ao contrário, esse trabalho se destina a explicar que as teorias acerca do conhecimento jurídico devem ser adotadas como corretas, como uma espécie de parâmetro para a formação dos argumentos a serem defendidos pelos operadores do Direito e, principalmente, para alcançar soluções justas e pacíficas para as demandas discutidas dentro de um processo judicial. Johannes Hessen (2003, p. 23) explica porque o conhecimento não alcança uma verdade absoluta:

Os conhecimentos tratados como verdadeiros possuem uma concordância entre a

'figura' que fora compreendida e o seu objeto. Um conhecimento é verdadeiro na

Rev. de Teorias da Justiça, da decisão e da argumentação jurídica | e-ISSN: 2525-9644| Evento Virtual| v. 6 | n. 1 | p. 55-75 | Jan/Jun. 2020 
medida em que seu conteúdo concorda com o objeto intencionado. Consequentemente, o conceito de verdade é um conceito relacional. Ele expressa um relacionamento, a saber, o relacionamento do conteúdo do pensamento, da 'figura', com o objeto. O próprio objeto, ao contrário, não pode ser verdadeiro nem falso. De certo modo, ele está para além da verdade e da inverdade. Uma representação inadequada, por sua vez, pode ser verdadeira, pois apesar de incompleta pode ser correta, se as características que contém existirem efetivamente no objeto.

A partir dessa ideia, é importante ter em mente que adotar o resultado de um processo cognitivo como uma verdade absoluta é perigoso, visto que o conhecimento está em constante evolução e todas as teorias por ele adotadas como paradigmas estão sujeitas à refutação. Enrique R. Aftalión, José Vilanova e Julio Raffo (2004, p. 34) afirmam que o conhecimento dogmático se baseia em verdades absolutas que não abrem margem para contestações críticas, buscando explicar o desconhecido por meio de proposições dogmáticas que simplesmente serão aceitas pelo homem, impedindo-o de ampliar seus conhecimentos por meio da investigação dessas proposições.

Hugo de Brito Machado Segundo (2008, p. 11) critica a visão dogmática da ciência do Direito baseada nos preceitos trazidos pelo positivismo jurídico ${ }^{\dagger}$, "porque nela, o cientista deveria partir das normas vigentes, tendo-as como dogmas, vale dizer, como algo indiscutível e inquestionável". O autor explica que o conhecimento jurídico não pode ser imposto e imutável, já que precisa se adaptar a realidade social, atendendo as suas demandas, com a verificação dos fatos que se apresentam.

Agostinho Marques Neto (2004) apresenta uma crítica pertinente sobre a aplicação do positivismo no processo de aquisição do conhecimento científico, afirmando que o "mito positivista" constantemente é utilizado nos Estados Modernos como uma forma de controle que favorece as classes dominantes em face das classes dominadas, tentando camuflar esse sistema de favorecimento desleal através do "manto ideológico" de segurança jurídica que é utilizado como instrumento de justificação para o pensamento positivista. Nesse ínterim, Ronald Dworkin (2002) explica que o positivismo jurídico pode ser ainda mais arbitrário quando uma ação judicial não pode ser resolvida por meio de uma norma jurídica específica, ou seja, nos

\footnotetext{
${ }^{\dagger}$ Para melhor entendimento do leitor, vale a pena explicar o que seria o pensamento positivista. Essa vertente surgiu, principalmente, com base na Teoria Pura do Direito inaugurada por Hans Kelsen (2015), em que a ciência jurídica deveria ser estudada e aplicada de maneira completamente apartada das outras ciências, inclusive das ciências sociais. Para ele, a pureza da ciência jurídica deve prevalecer como medida de obtenção de uma maior segurança jurídica, de que o Estado ficaria limitado aos mandamentos legais devidamente positivados, em que os operadores do direito estariam submetidos às regras estipuladas e os juízes funcionariam meramente como "bocas da lei”, julgando estritamente de acordo com o ordenamento jurídico, podendo apenas decidir, de maneira mais discricionária, em caso de possíveis lacunas que venham a aparecer.
}

Rev. de Teorias da Justiça, da decisão e da argumentação jurídica | e-ISSN: 2525-9644| Evento Virtual| v. 6 | n. 1 | p. 
casos em que se apresentam lacunas no ordenamento jurídico, visto que o julgador tem, com base em tal teoria o "poder discricionário" de julgar o conflito como achar conveniente.

Ante a isso, a melhor solução para os entraves criados pelas limitações da cognição humana no processo de aquisição do conhecimento científica seria a adoção da teoria falibilista preconizada por Karl Popper (2001), a qual determina que, para se alcançar um conhecimento verdadeiramente seguro e científico, as presunções adotadas como corretas devem sempre ser questionadas, ou seja, a atitude do pesquisador deve sempre buscar falsear, mediante refutações, as teorias que são aceitas como verdadeiras. Caso se comprove, por meio da tentativa de falsificação, que determinada ideia é válida, isso é positivo para o avanço científico, pois as teorias aceitas se tornam ainda mais fortes (ainda devendo se sujeitar a possíveis refutações, para não se adote uma atitude dogmática); entretanto, caso uma teoria venha a ser derrotada por outra, isso também é extremamente produtivo para a construção da ciência jurídica, já que uma ideia válida irá superar uma ideia que não merece mais ser aplicada. O autor (POPPER, 2001, p. 26) explica: "Portanto, a minha tese principal é que a novidade da ciência e do método científico, que o distingue da abordagem pré-científica, é a sua atitude conscientemente crítica em relação às tentativas de solução; toma uma parte activa nas tentativas de eliminação, nas tentativas de criticar e falibilizar".

Hans Georg Gadamer (2005) concorda com esse entendimento, afirmando que a racionalidade merece ser valorizada entre os indivíduos, superando as barreiras criadas pelos preconceitos advindos de uma compreensão que não respeita o processo hermenêutico científico, em que as convicções podem ser reafirmadas ou superadas. Os preconceitos, que nada mais são do que a obediência à dogmas já determinados, induzem ao erro no processo cognitivo, inclusive, na análise das provas. Os elementos probatórios visam uma maior aproximação da veracidade dos fatos apresentados em determinada demanda, para que assim, os operadores do direito possam criar presunções sobre quais as soluções seriam eficazes para solucionar tal questão.

3 Qual a relevância dos fatos para que se atinja a tutela jurisdicional?

As provas procuram fundamentar as decisões a partir de presunções. Estas, por seu turno, buscam "alcançar a verdade dos fatos" para que se atinja uma decisão mais justa. Diante disso, surge a necessidade de discutir a relevância da consideração dos fatos para que se atinja a tutela jurisdicional de maneira eficaz.

Rev. de Teorias da Justiça, da decisão e da argumentação jurídica | e-ISSN: 2525-9644| Evento Virtual| v. 6 | n. 1 | p. $55-75$ | Jan/Jun. 2020 


\section{AS PROVAS NO PROCESSO JUDICIAL SOB A ÓTICA DA EPISTEMOLOGIA JURÍDICA}

Euger Ehrlich (1986), entende que o que nasce da normatização estatal é apenas uma pequena parcela do Direito; para ele, a ciência jurídica nada mais é do que o reflexo da realidade social vigente e suas exigências para a aplicação prática da tutela jurisdicional por seus operadores. $\mathrm{O}$ autor afirma que o desenvolvimento do Direito se dá a partir do surgimento e transformação das instituições sociais, tendo estas como ponto de partida para a sua estruturação. Defende que a intervenção direta do poder de polícia ou as decisões judiciais emanadas pelos órgãos públicos competentes também conseguem influenciar no desenvolvimento do Direito, contudo, é impossível ignorar que a cada momento, nas sociedades modernas, são criadas instituições novas ou as já existentes investem em transformações para evoluir, independentemente das determinações advindas da legislação estatal; afirmando que “o Direito muda, porque mudam as pessoas e as coisas" (EHRLICH, 1986, p. 300). Diante disso, Eugen Ehrlich ressalta a importância da apreciação dos fatos para a ciência jurídica, na medida em que, apenas por meio destes, seria possível apreciar as demandas sociais que necessitam da proteção do Direito.

Em consonância, Michelle Taruffo (2009) defende que para alcançar uma solução justa de uma decisão, com a correta compreensão e aplicação da norma jurídica, é necessário que exista uma crença de veracidade sobre os fatos trabalhados. A verdade dos fatos passa a ser a condição necessária à correta aplicação de qualquer norma jurídica, afirmando o autor que os meios de prova são os elementos utilizados para estabelecer a verdade acerca dos fatos da causa.

As provas, muitas vezes, podem parecer incertas, duvidosas e discutíveis a partir de determinadas argumentações dentro do processo. Diante disso, justificadamente, Michelle Taruffo (2009) adere ao pensamento de Karl Popper (2001), no que se refere a impossibilidade de apreensão da realidade, mas, ainda assim, a continuidade da busca incessante por uma teoria mais próxima da verdade, já que não seria eficaz que as decisões judiciais se baseassem apenas em normas, sob o viés positivista, sem uma preocupação com o caso concreto propriamente dito. Surge, a partir disso, a necessidade dessa busca pela verdade mais próxima dos fatos.

Salienta-se que essa proposta não sugere o contrário, ou seja, que os fatos ganhem respaldo exclusivo dentro de um processo, pois isso recairia em arbitrariedade. Contudo, conforme as críticas ao positivismo destacadas no tópico anterior, a aplicação exclusiva das normas jurídicas poderia ocasionar uma impessoalidade indesejada por parte dos juristas envolvidos em determinada demanda, principalmente do julgador que seria o responsável por

Rev. de Teorias da Justiça, da decisão e da argumentação jurídica | e-ISSN: 2525-9644| Evento Virtual| v. 6 | n. 1 | p. $55-75$ | Jan/Jun. 2020 
solucionar devidamente a questão, podendo essa ser prejudicada por mero formalismo ou por questões legais que não conseguem sanar demandas da realidade social, a partir da constante interação dos grupos que a compõem. Assim, a supervalorização do direito positivado e do formalismo exacerbado é perigosa para a consolidação da justiça, o contrário, que seria a supervalorização dos fatos em detrimentos das normas, também levaria a arbitrariedade. Michele Taruffo (2009) supõe que a verdade dos fatos em litígio pode ser determinada mediante a adoção de "crenças de veracidade", afirmando: "Algunas cuestiones concernientes al problema de la verdad judicial y la función de los medios de prueba surgen porque los 'hechos en litigio' o los 'hechos de la causa' necesariamente se determinan sobre la base de las normas jurídicas que se aplican a fin de resolver el caso".

A análise dos elementos probatórios supera os limites dos mandamentos legais e aproxima a compreensão em torno dos fatos. Constantemente, os fatos são definidos por normas que incluem termos valorativos como "bom", "normal", "razoável", etc. Esses tipos de fatos, ao serem analisados, estão carregados valorativamente. Isso não implica que seja sem sentido falar de "crença de veracidade" de tal fato e que esta crença não possa ser estabelecida através da análise das provas. A busca pela "verdade" dos fatos cria "presunções", que refletem a crença de veracidade adquirida por meio dos elementos valorados como provas. Essas presunções serão tratadas como corretas, até que sejam refutadas através da contraposição de teorias, que são debatidas pela dialética que compõe os processos judiciais, sendo este o procedimento essencial para que se presuma a verdade ou a falsidade dentro de um litígio.

Essa concepção acerca da refutação das teorias criadas a partir da análise dos fatos é justificada pela teoria do falsificacionismo de Karl Popper (2001), a respeito do processo de aquisição do conhecimento científico. Logo, os fatos devem ser reconstruídos pelo julgador tomando como base os meios de prova disponíveis. Quando se fala na verdade de um fato, na realidade está se falando na verdade de um enunciado acerca desse fato. Em consequência, o que se prova e se demonstra em um processo judicial é a verdade ou a falsidade dos enunciados sobre os fatos em litígio, que se alcança por meio do processo de tentativa e erro a partir da análise do conjunto probatório.

Após a análise dos fatos, são criadas teorias acerca da veracidade dos mesmos, ensejando a adoção de presunções, que podem ser refutadas ou confirmadas ao serem confrontadas com outras teorias igualmente relevantes. Essa logística se justifica pela busca da 
determinação dos fatos, pois só depois de determinados eles podem ser valorados, ou seja, pode ser aplicada uma norma adequada aos mesmo. Portanto, a valoração dos fatos nada mais é do que a sua interpretação por meio de normas jurídicas, visando equilibrar o caso concreto proposto com a legislação vigente que envolve o assunto.

$4 \quad$ Qual o papel das presunções?

A ideia de presunção se aproxima do que podemos entender como um paradigma, retomando a teoria proposta por Thomas Kuhn (2005). Contudo, as presunções são direcionadas a busca de uma resposta por meio dos elementos fundamentadores de um determinado fato; a presunção é o resultado das teorias advindas da análise dos elementos probatórios, sendo alcançada por meio do raciocínio lógico aplicado ao verificar tais elementos, por isso, possui um papel fundamental na valoração das provas (processo de adequação dos fatos com as normas jurídicas). Portanto, podemos afirmar que a presunção não é um fato específico, mas uma medida provisória estimativa desses fatos; sendo assim, determinada presunção, quando adotada, está constantemente sujeita às hipóteses de refutações, aplicando a falibilidade.

Nicholas Rescher (2006) inaugurou a ideia acerca das presunções jurídicas, explicando que esses institutos encontraram o seu mais importante papel na valoração normativa dos fatos, justificando que as presunções exigem que um tipo normativo aceite um fato determinado. Preleciona (RESCHER, 2006, p. 04):

A presumption is in tentative and provisional possession of the cognitive terrain, displaced by something that is evidentially better substantiated.6 A presumption is a putative fact which, while in the circumstances perhaps no more than probable or plausible, is nevertheless to be accepted as true provisionally - allowed to stand until concrete evidential counterindications come to view. Presumption is thus typified by the idea of "innocent until proven guilty."

And so presumptions, though possessed of significant probative weight, will in general be defeasible - that is, subject to defeat in being overthrown by sufficiently weighty countervailing considerations.

A presunção não é um fato específico, mas uma medida provisória aproximada. É exequível, por ser provisoriamente considerada verdadeira e, por isso, considerada segura, até que seja derrotada: permanece no lugar a menos e até que seja deslocada por falseamentos que a desestabilizem. Desse modo, aplica-se o falsificacionismo de Karl Popper (2001), às presunções que foram criadas por meio do processo cognitivo para a análise dos casos, visto que essas presunções podem ser refutadas a todo momento, concordando com o pensamento demonstrado por Hugo Machado Segundo e Raquel Machado (2014).

Rev. de Teorias da Justiça, da decisão e da argumentação jurídica | e-ISSN: 2525-9644| Evento Virtual| v. 6 | n. 1 | p. 55-75 | Jan/Jun. 2020 
As justificativas para a adoção de uma presunção devem coincidir com os elementos fáticos e probatórios, visando alcançar a melhor resposta para determinada questão judicial, por meio da presunção adotada. Mas, independentemente de sua fundamentação, o funcionamento operacional das presunções é substancialmente o mesmo. Em todo caso, uma presunção é um pretendente plausível da verdade cuja as credenciais podem se revelar insuficientes, um corredor em uma corrida pode não ganhar. A "aceitação" de uma proposição como uma verdade meramente presuntiva não é aceitação, mas episódios altamente provisórios e condicionais inclinação temática em relação a ela, uma inclinação que fica muito aquém da realidade.

Desta feita, a presunção é o resultado gerado a partir da "crença de veracidade" adquirida por meio da análise dos fatos, sendo assim, é relativa, demonstrando a importância de uma reanálise dos elementos probatórios diante das diversas fases processuais. Poderíamos conceituar a presunção como um recurso informativo que serve para fechar uma lacuna debilitante, que seria a dificuldade em se alcançar a verdade absoluta e certeira sobre os fatos apresentados, que acaba por gerar uma lacuna essencial para a solução da demanda posta em um processo, tornando, desse modo, necessária a adoção de uma presunção para que se possa alcançar uma solução justa.

A presunção, uma vez refutada e confirmada a sua validade, serviria como suporte fático da norma, uma espécie de ponto de partida para um debate eficiente, que encontra na presunção o seu suporte. Dessa maneira, a dialética é um elemento fundamental no processo, pois a partir dos debates travados entre as partes e o julgador, torna-se possível confirmar ou falsificar a presunção que fora adotada como mais válida até então; a dialética utiliza a presunção como um mecanismo para fortalecer os argumentos das partes envolvidas no processo, criando diversas possibilidades para a valoração das provas e apresentando propostas diferentes para se dirimir os litígios. É por isso que o contraditório deve ser respeitado dentro do trâmite processual, independentemente da área do Direito que esteja sendo travado determinado embate.

Jurgen Habermas (2003) destaca a importância da linguagem para a resolução dos conflitos, por meio do aprimoramento da compreensão em torno de uma determinada demanda. Explica que as divergências culturais e o embate entre teorias só pode ser plenamente resolvido mediante os mecanismos linguísticos, que permitem, de maneira satisfatória, a compreensão dos indivíduos sobre determinada presunção considerada verdadeira, com o devido confronto 
de seus entendimentos. O autor (HABERMAS, 2003) pressupõe a "reviravolta linguísticopragmática" destacando a relevância da dialética para aprimorar a teoria do conhecimento. Para ele, a linguagem é o elemento central das relações humanas. Por isso, a dialética é o caminho fundamental para se atingir um conhecimento mais "seguro" sobre uma questão apresentada, com respeito a diversos pontos de vistas em busca de uma verdade plausível. Isso possui plena correspondência com os meios de discussão no âmbito jurídico.

A dialética entre os sujeitos dentro do embate travado em torno de uma demanda é essencial para a validade das normas jurídicas e o alcance da legitimidade do Direito que está sendo aplicado, como medida de garantia do devido processo legal e do arcabouço principiológico constitucional. Não é por meio do positivismo exacerbado e de seu excesso de formalismo que podemos adquirir a segurança jurídica, mas sim por meio da dialética e da garantia de um debate justo e igualitário, seguindo os pressupostos do contraditório e da ampla defesa, visto que, o embate entre teorias é a melhor forma de se adquirir conhecimento científico, e isso não seria diferente para a ciência do Direito e de sua aplicação na prática jurídica. A dialética objetiva o gerenciamento de informações, por meio de um procedimento epistêmico e cognitivo.

5 Como as provas merecem ser "trabalhadas" pelos operadores do Direito?

O nosso ordenamento jurídico, por meio de diversos mandamentos, encontrados em diferentes complexos normativos, das diferentes áreas do Direito, tentam determinar como deve se dar o trabalho cognitivo para a análise das provas. Como exemplos, poderíamos citar o artigo $5^{\circ}$, inciso LVI, da Constituição Federal (BRASIL, 1988); artigo 369 a 380, do Código de Processo civil (BRASIL, 2015); artigo 200, do Código de Processo Penal (BRASIL, 1941), dentre outros. Percebe-se, a partir da breve demonstração desses exemplos, que cada área considera as provas de maneira distinta, a partir dos objetivos que a norteiam.

Como a verdade é algo inalcançável, conforme incessantemente explicado nos tópicos anteriores do presente trabalho, percebe-se que as provas sempre serão indiretas, em algum grau. Por isso, para alcançar uma valoração sensata dos meios de prova, é necessário que se investigue todos os indícios presentes nos autos, já que uma "seleção" das provas que merecem valoração jurídica poderia acarretar em grave insegurança e prejuízo à defesa, que é uma 
garantia fundamental do devido processo legal, por meio do artigo $5^{\circ}$, incisos $\operatorname{LIV}^{\star}$ e $\mathrm{LV}^{\S}$, da Constituição Federal (BRASIL, 1988).

$\mathrm{Na}$ tentativa de limitar como deve proceder o livre convencimento do juiz, o ordenamento jurídico pátrio determinou a obrigatoriedade de motivação das decisões, que se dá majoritariamente por meio da valoração das provas apresentadas nos autos, e também é previsto como um preceito fundamental, sendo estipulado pelo artigo 93, inciso IX $^{* *}$ da Constituição Federal (BRASIL, 1988). Diante disso, os magistrados devem apresentar as razões que a sua decisão com base no conjunto probatório e nas normas vigentes, contando com o cuidado de analisar todas as provas que foram trazidas aos autos processuais e influenciaram na formação do seu "livre convencimento", que é limitado pelo devido processo legal e pela proibição do cerceamento de defesa.

Rodolfo Wild (2016) expressa que o conjunto de teorias que tentam explicar o livre convencimento normalmente são encontradas no âmbito do senso comum ${ }^{\dagger \dagger}$, e se dão a partir de uma "ilusão pacificadora". Explica que "o livre convencimento figura como um princípio geral sobre a prova" (WILD, 2016, p. 169), contudo, critica a sua aplicação na prática jurídica, visto que é um princípio muito abstrato que acaba dando a permissão para que os juízes decidam um processo judicial com base, puramente, em suas convicções subjetivas, dando margem a uma postura autoritária por parte desses julgadores, não podendo atingir, muitas vezes, uma solução realmente eficaz e pacificadora como objetiva o devido processo legal. Seguindo o mesmo entendimento, expressa Michele Taruffo (2019, p. 235)

Antes de qualquer coisa, é oportuno recordar que o princípio do livre convencimento do juiz, que hoje em dia tem aplicação largamente predominante nos ordenamentos processuais modernos, não implica, de fato, que o juiz esteja desvinculado de critérios de racionalidade que devem governar seu raciocínio: tal princípio admite que o juiz valore as provas fazendo uso de amplo poder discricionário, mas isso não significa que ele possa confiar em uma intuição subjetiva - que seria substancialmente arbitrária - ao estabelecer se uma hipótese relativa a um fato foi ou não confirmada pelas provas disponíveis.

\footnotetext{
* Art. $5^{\circ}$, LIV, CF. Ninguém será privado da liberdade ou de seus bens sem o devido processo legal.

$\S$ Art. $5^{\circ}, \mathrm{LV}, \mathrm{CF}$. Aos litigantes, em processo judicial ou administrativo, e aos acusados em geral são assegurados o contraditório e ampla defesa, com os meios e recursos a ela inerentes.

** Art. 93, IX, CF. Todos os julgamentos dos órgãos do Poder Judiciário serão públicos, e fundamentadas todas as decisões, sob pena de nulidade, podendo a lei limitar a presença, em determinados atos, às próprias partes e a seus advogados, ou somente a estes, em casos nos quais a preservação do direito à intimidade do interessado no sigilo não prejudique o interesse público à informação.

† Johannes Hessen (2003) explica o "senso comum" como juízos cognitivos predeterminados, adquiridos por meio das interações sociais e históricas dos indivíduos, a partir de suas experiências cotidianas.
} 


\section{AS PROVAS NO PROCESSO JUDICIAL SOB A ÓTICA DA EPISTEMOLOGIA \\ JURÍDICA}

A maior problemática envolvendo o livre convencimento se dá quando o julgador, normalmente constituído pela pessoa do magistrado, já começa a analisar uma demanda e o conjunto probatório que rodeiam os fatos apresentados, utilizando por base uma ideia predeterminada, que acarreta em uma visão dogmática sobre o assunto, o que pode vir a contaminar sua percepção acerca das provas. Em casos de dúvidas sobre qual visão adotar, muitas vezes, recorrem à consulta dos precedentes. $\mathrm{O}$ uso de jurisprudências para a resolução de litígios judiciais é um importante mecanismo de harmonização e equilíbrio entre as decisões prolatadas, ensejando a verificação de proporcionalidade entre as soluções adotadas. Entretanto, os precedentes, mesmo que sejam semelhantes aos fatos apresentados em determinado processo, não podem prevalecer em relação aos meios de prova que explicam determinado caso, engessando o processo cognitivo do julgador.

Um problema prático sobre essa questão envolvendo o livre convencimento dos magistrados são as hipóteses em que o julgador indefere a produção dessas provas, fundamentando com base no argumento de que já teria formado o seu convencimento sobre a questão, considerando desnecessária a produção de novas provas. Contudo, ele jamais poderia ter formulado a sua cognição sobre os fatos apresentados antes de analisar todos os elementos que as partes tenham apresentado ou visassem apresentar, mesmo que ainda não tivessem sido produzidos nos autos, visto que tais provas poderiam comprovar uma teoria completamente nova, criando uma nova presunção sobre o assunto. Essa negação por parte do magistrado acarretaria em grave cerceamento de defesa.

Ronald Dworkin (2002) preconiza a Teoria da Controvérsia, buscando estabelecer os padrões que os juízes devem utilizar para decidir os casos jurídicos de sua competência. Os julgadores devem admitir que as respostas adotadas por eles são apenas respostas, não podendo ser consideradas como verdadeiramente corretas, estando sujeitas a refutações por meio do embate argumentativo racional.

Em contrapartida, apesar de as decisões tomadas por juízes serem falíveis, não atingindo, muitas vezes, o convencimento das partes de seus procuradores, ainda assim é mais seguro deixar essa decisão vigorar do que buscar medidas alternativas por intermédio de critérios morais e políticos. Logo, as decisões judiciais deverão ser presumidas como verdadeiras, quando devidamente motivadas, podendo vir a ser contraditadas por meio do falibilismo inerente ao método argumentativo que consubstancia toda a prática jurídica.

Rev. de Teorias da Justiça, da decisão e da argumentação jurídica | e-ISSN: 2525-9644| Evento Virtual| v. 6 | n. 1 | p. $55-75$ | Jan/Jun. 2020 
A partir desse entendimento, Ronald Dworkin (2002) afirma que é necessário que se adote a possibilidade de uma resposta correta, mesmo que falível, para uma determinada decisão judicial, buscando atingir uma solução justa para determinada demanda. Preleciona (DWORKIN, 2002, p. 435) que "uma proposição do direito pode ser considerada verdadeira se for mais coerente do que a proposição contrária com a teoria jurídica que justifique melhor o direito estabelecido. Pode ser negada como falsa se for menos coerente com essa teoria do direito do que a contrária". Entretanto, como medida de proteção contra possíveis arbitrariedades em suas ações, os magistrados devem ter uma atitude humilde perante o "mito da verdade", tendo consciência de que as razões que justificam suas crenças não são conclusivas.

Diferentemente do comportamento que deve ser adotado pelos magistrados, as partes, por meio de seus procuradores, podem indicar as provas de maneira favorável a tese que pretendem sustentar, tendo a permissão de valorar tais provas de maneira favorável e parcial para si, criando uma teoria que pode omitir determinadas provas que a prejudique. É essa permissão que consubstancia a dialética dentro do processo e que consolida um debate enriquecedor sobre os diferentes pontos de vista em relação a determinada demanda.

Seria papel dos advogados e dos outros profissionais que exercem a defesa das partes, destacar as falhas na interpretação das provas dos autos. Contudo, os magistrados não precisam esperar pela manifestação acerca das falhas nos elementos probatórios, eles podem, de ofício, solicitar a produção de novas provas que considerem relevantes para se chegar ao maior conhecimento dos fatos que envolvem a demanda, partindo da ideia de que essa maior produção probatória seria essencial para a formação de uma cognição segura sobre a demanda.

Sobre o contraditório adotado pelos juristas dentro de um processo judicial, afirma Michele Taruffo (2009, p. 223): "O contraditório processual gera a dúvida, mostrando soluções diferentes do conflito entre as partes, mas o processo não pode terminar deixando de resolver essa dúvida". São excepcionais os casos em que não se chega em uma solução, ou que não é necessária a análise probatória para chegar em determinado acordo, por exemplo. Lara Teles (2019, p. 237), ao adentrar na discussão sobre a função cognitiva do contraditório, defende que o embate argumentativo entre as partes aprimora a valoração dos elementos probatórios dentro do processo, possibilitando a adoção de soluções mais justas, afirmando que: 
[...] a dialeticidade processual, por propiciar um confronto entre versões, com explicações advindas de ambas as partes, contribui para evitar decisões judicias fundamentas meramente em vieses de confirmação. O contraditório efetivo, portanto, é um parâmetro valorativo relevante para por em baila as limitações cognitivas do juiz e seus vieses.

Trata-se de uma tentativa de controle à arbitrariedade das heurísticas do pensamento do julgador, embora se reconheça que a plena prevenção ao enviesamento somente ocorreria com medidas mais drásticas, como a exclusão física do inquérito policial e a atuação do juízo de garantias.

Portanto, conclui-se que o contraditório efetivo no decorrer do processo, seja na fase de dilação probatória, seja na fase de alegações finais, é um aspecto essencial para que seja conferido o devido valor a uma determinada prova.

O magistrado atua dentro desse debate dialético das partes como um terceiro imparcial e, por isso, não pode adotar determinada teoria, analisando apenas as provas que a fundamentam. Isso seria completamente contrário ao seu dever de imparcialidade e cercearia os elementos de defesa apresentados pelas partes. Sem contar que prejudicaria o objetivo principal do procedimento processual, que deve buscar uma maior aproximação com a realidade dos fatos, para que se possa aplicar uma solução justa.

As provas pertencem ao processo, em busca da "verdade" dos fatos para alcançar a tutela jurisdicional, por causa disso, o magistrado pode pedir esclarecimentos sobre as provas colacionadas aos autos, devendo levar em conta todos os elementos que emergem no processo. Como medida de segurança jurídica, a decisão deve ser motivada e racional, obedecendo as regras e os princípios ${ }^{*}$ que norteiam o ordenamento jurídico, aplicando o método cognitivo de presunções e refutações que permita o controle dos elementos probatórios e determine a validade destes. Portanto, diante do respeito ao princípio da legalidade, o magistrado deve aplicar, dentre as interpretações possíveis, aquela que mais se adéque aos fatos e as normas, com a valoração justa dos meios de prova.

Susan Haack (2002) explica que o resultado obtido por meio do embate entre teorias, buscando o entendimento mais coerente a partir dos elementos probatórios dentro de um processo, merece ser constantemente alvo de contraditório, já que a busca por novos dados cognitivos deve continuar e, a partir disso, novas teorias devem ser enfrentadas, podendo o entendimento adotado como correto ser refutado ou superado. $\mathrm{O}$ falsificasionismo Popperiano \# Ronald Dworkin (2002, p. 39) diferencia o conceito de regras e de princípios, explicando: "A diferença entre
princípios jurídicos e regras jurídicas é de natureza lógica. Os dois conjuntos de padrões apontam para decisões
particulares acerca da obrigação jurídica em circunstâncias específicas, mas distinguem-se quanto à natureza da
orientação que oferecem. As regras são aplicáveis à maneira do tudo-ou-nada. Dados os fatos que uma regra
estipula, então ou a regra é válida, e neste caso a resposta que ela fornece deve ser aceita, ou não é válida, e neste
caso em nada contribui para a decisão".

Rev. de Teorias da Justiça, da decisão e da argumentação jurídica | e-ISSN: 2525-9644| Evento Virtual| v. 6 | n. 1 | p. 55-75 | Jan/Jun. 2020 
se adequa perfeitamente a esse entendimento e explica também a análise das provas no processo, pois além de analisar o contexto probatório apresentado pelas partes, o magistrado possui o dever de buscar uma maior produção probatória, visando confirmar ou falsificar o entendimento adotado.

No nosso sistema jurídico, o direito à produção de provas não é absoluto, mesmo sendo garantida a ampla defesa e o contraditório. Isso ocorre quando a prova é ilícita, impertinente, desnecessária ou impraticável (MACHADO SEGUNDO; MACHADO, 2014). Desses elementos, merece destaque as discussões sobre provas ilícitas, pois estas não podem ser indeferidas quando há a possibilidade de alterar a análise cognitiva do julgador. Sendo assim, uma escuta telefônica ilegal (nos termos dos mandamentos legais que estipulam como deve se dar a aquisição dessas provas), deve ser considerada válida quando visa comprovar a inocência da pessoa que está sendo acusada nos autos, visto que o princípio da inocência se sobrepõe sobre a ideia de provas ilícitas, diante do "sopesamento entre princípios como normas de direito fundamental atribuídas" (ALEXY, 2015, p. 99).

Ademais, uma das questões mais importantes dentro da dialética jurídica a respeito da análise probatória é a de quem recai o ônus de provas. Regra geral, o ônus da prova é de quem deseja provar algo. Posto isso, a inversão do ônus da prova deve ser devidamente justificada e, geralmente si dá, ou em hipóteses determinadas pela lei, ou por meio de decisões incidentais que considerem mais "fácil" para a parte adversa conceder a prova sobre determinada demanda.

O ônus da prova advém da ideia de contraditório e da ampla defesa e representa uma concepção correlativa e coordenada com a concepção acerca da presunção, que é perceptível em toda a extensão da investigação racional. Nicholas Rescher (2006) explica que a presunção e o ônus da prova são as duas faces da mesma moeda, pois no momento em que se busca refutar uma presunção, recai o ônus da prova e, no momento em que se adota uma presunção, o uso do ônus da prova deixa de ser necessário. O autor defende que a presunção está intimamente ligada à ideia de ônus da prova (ônus probandi), que também está na raiz de uma concepção legal. Funciona no contexto de um processo contraditório em que uma parte está se empenhando parta estabelecer um entendimento e outro busca refutar tal questão antes da análise do tribunal.

Alguns elementos probatórios criam presunções mais "fortes" do que outras, é por isso que a validação dos meios de aquisição de prova é tão relevante. Quando os elementos Rev. de Teorias da Justiça, da decisão e da argumentação jurídica| e-ISSN: 2525-9644| Evento Virtual| v. 6 | n. 1 | p. 55-75 | Jan/Jun. 2020 
probatórios demonstram de maneira mais nítida como se deu a ocorrência de determinados fatos, pode-se considerar esses elementos mais "fortes" para a formação da cognição nos autos. Em contrapartida, as provas "frágeis" são aquelas que não conseguem demonstrar os fatos de maneira clara e evidente e, desse modo, carecem de uma melhor argumentação e/ou de uma complementação com outras provas.

Percebe-se, a partir das discussões estabelecidas, que o procedimento argumentativo, inerente aos embates travados dentro dos processos judiciais, por meio dos mecanismos de contraditório e de ampla defesa, permitem uma cognição mais apurada a respeito dos fatos apresentados em litígio, alcançando presunções mais próximas da verdade, para que assim, seja possível determinar soluções mais justas para os casos concretos. É por meio desses recursos baseados no contraditório que se garante a segurança dos procedimentos judiciais, visto que eles são constantemente revalidados pelos mecanismos linguísticos argumentativos. Desta feita, o método científico envolve observações empíricas, construção de hipóteses a partir dessas observações e testar essas hipóteses para que elas possam ser admitidas como teorias válidas. Por fim, as análises feitas a partir dos elementos probatórios se resumem ao simples conjunto de julgamentos humanos; ou seja, pessoas que observam os dados e determinam, a partir deles, os resultados alcançados.

Os problemas ligados aos meios de aquisição de prova não significam que o sistema jurídico seja hostil aos métodos científicos para a valoração dessas provas, na realidade, apenas demonstram que esse sistema deve aprimorar esses métodos, trazendo a ciência do embate existente dentro do processo de investigação probatória para dentro dos órgãos jurídicos, principalmente nos tribunais, nos quais os julgadores determinam as soluções consideradas cabíveis para determinado caso concreto. Esse método se dá por meio da dialética, que se fundamenta no embate entre teorias em torno das provas apresentadas pelas partes, possibilitando a refutação das presunções adotadas para decidir uma questão, trazendo uma maior segurança para a tutela jurisdicional que fora prestada. A possibilidade do falseamento de presunções por meio da dialética permite a autocorreção do processo cognitivo.

\section{Conclusão}

A cognição humana é limitada e isso ocasiona um grave problema epistemológico de como esses elementos probatórios deverão ser percebidos para que se alcance uma solução

Rev. de Teorias da Justiça, da decisão e da argumentação jurídica | e-ISSN: 2525-9644| Evento Virtual| v. 6 | n. 1 | p. 55-75 | Jan/Jun. 2020 
justa. Diante dessa limitação, considerasse que a verdade absoluta jamais será alcançada, sob a perspectiva da teoria do conhecimento científico. Adotar determinado preceito como correto e imutável, assim como propõe as vertentes ligadas ao positivismo jurídico, seria algo extremamente perigoso e arbitrário, vindo a consolidar uma compreensão jurídica dogmática e que não atende às demandas sociais que lhe são postas.

O melhor mecanismo a ser adotado como medida de superação da compreensão dogmática determinada pelo positivismo enraizado em nossos procedimentos jurídicos, em que as normas são supervalorizadas em detrimento dos fatos, é a adoção da método falibilista proposto por Karl Popper, em que todos as compreensões adquiridas por meio da análise dos elementos probatórios merecem ser refutadas, ou mediante os instrumentos linguísticos argumentativos que compõem a dialética, ou mediante a produção de novas provas, que também serão valoradas e refutadas através do contraditório e da ampla defesa.

A observação do contexto fático proposto em uma demanda judicial é essencial para que compreenda por que linha seguir no processo valorativo das provas, adequando esses fatos às normas jurídicas vigentes, admitindo ambos em patamar de equilíbrio. É a partir do estudo dos fatos que se pode chegar mais próximo da realidade que compõe o litigio apresentado, criando assim, uma crença de veracidade em torno dele. Essa crença de veracidade permite a formulação de presunções sobre qual a solução mais justa para determinado caso concreto. Entretanto, essas presunções são respostas sujeitas à constante verificação e falseamento, visto que a verdade é inalcançável e novos elementos podem vir a surgir no decorrer do trâmite processual.

É por isso que os operadores do Direito devem adotar uma postura "humilde" em relação às presunções que estão defendendo para resolver uma questão judicial, reconhecendo as limitações acerca da sua compreensão sobre os fatos apresentados e admitindo o falseamento de suas próprias teorias em meio ao debate proporcionado pelo contraditório. Logo, os magistrados devem agir como terceiros imparciais, analisando todas as provas e os argumentos postos pelas partes, podendo, inclusive, solicitar maior produção de provas, caso seu convencimento ainda não esteja devidamente formado. Esses profissionais devem buscar afastar os seus critérios valorativos pessoais e predeterminando, afastando uma visão "preconceituosa" sobre determinada demanda que venha a surgir. Como medida para evitar a possível arbitrariedade por parte dos juízes, a decisão deve obedecer ao preceito fundamental 
da motivação, devendo cada argumento e cada prova ser analisada especificamente pelo julgador, demonstrando devidamente os motivos pelos quais foi formado o seu livre convencimento.

As partes, por meio de seus procuradores, devem assumir o seu papel no contraditório, fazendo-se valer dos utensílios disponibilizados pelo ônus da prova e dos instrumentos linguísticos argumentativos para defender suas teses e impossibilitar a ocorrência de arbitrariedades dentro do trâmite processual. Portanto, o método de falseamento das presunções adotadas como corretas e a dialética inerente ao procedimento judicial do contraditório permitem não só uma análise justa dos elementos probatórios, bem como, garantem a segurança jurídica dentro do processo judicial, na medida em que todos os atos e teorias estão sujeitos à recursos e reanálises. Sendo assim, podemos considerar que o que garante a segurança jurídica não é a ideia positivista de obediência a norma, mas sim, a eficácia da dialética e do contraditório dentro dos processos judiciais, como medida de preservação do devido processo legal e do Estado Democrático de Direito.

\section{$7 \quad$ Referências}

AFTALIÓN, Enrique R.; VILANOVA, José; RAFFO, Julio. Introducción al derecho. Buenos Aires: Abeledo-Perrot, 2004.

ALEXY, Robert. Teoria dos direitos fundamentais. Trad. Virgílio Afonso da Silva. São Paulo: Malheiros, 2015.

BACHELARD, Gaston. A formação do espírito científico: contribuição para uma psicanálise do conhecimento. Tradução Esteia dos Santos Abreu. Rio de Janeiro: Contraponto, 1996.

BRASIL. Constituição (1988). Constituição da República Federativa do Brasil. Brasília: Senado Federal, 1988.

BRASIL. Código de Processo Civil (2015). Lei n. 13.105. Brasília: Presidência da República, 2015.

BRASIL. Código de Processo Penal (1941). Decreto Lei n. 3.689. Brasília: Presidência da República, 1941.

DWORKIN, Ronald. Levando os direitos a sério. Trad. Nelson Boeira. São Paulo: Martins Fontes, 2002.

FERNANDES, Lara Teles. Standards probatórios e epistemologia jurídica: uma proposta interdisciplinar para a valoração do testemunho no processo penal. Fortaleza: Universidade Federal do Ceará, Programa de Pós-Graduação em Direito, Mestrado, 2019.

FEYERABEND, Paul. A ciência em uma sociedade livre. Trad. Vera Joscelyne. São Paulo: Unesp, 2011.

Rev. de Teorias da Justiça, da decisão e da argumentação jurídica | e-ISSN: 2525-9644| Evento Virtual| v. 6 | n. 1 | p. 55-75 | Jan/Jun. 2020 
GADAMER, Hans-Georg. Verdade e Método. Trad. de Flávio Paulo Meurer. 7. ed.. Petrópolis: Vozes, Bragança Paulista: Editora Universitária São Francisco, 2005.

HAACK, Susan. Filosofia das lógicas. Tradução de Cezar Augusto Mortari e Luiz Henrique de Araújo Dutra. São Paulo: Unesp, 2002.

HABERMAS, Jürgen. Truth and justification. Translated by Barbara Fultner. Massachusetts: MIT Press, 2003.

HESSEN, Johannes. Teoria do conhecimento. Trad. João Vergílio Gallerani Cuter. São Paulo: Martins Fontes, 2003.

KELSEN, Hans. Teoria pura do Direito. Trad. João Baptista Machado. São Paulo: Martins Fontes, 2015.

KUHN, Thomas S. A estrutura das revoluções científicas. Tradução de Beatriz Vianna Boeira e Nelson Boeira. 9.ed. São Paulo: Perspectiva, 2005.

MACHADO SEGUNDO, Hugo de Brito. Por que dogmática jurídica? Rio de Janeiro: Forense, 2008.

MACHADO SEGUNDO, Hugo de Brito; MACHADO, Raquel Cavalcanti Ramos. Prova e verdade em questões tributárias. Coord. Hugo de Brito Machado. Revista do Instituto do Direito Brasileiro, n. 2, ano 3, 2014.

MARQUES NETO, Agostinho Ramalho. A ciência do direito: conceito, objeto, método. 2 ed. Rio de Janeiro: Renovar, 2004.

POPPER, Karl. A vida é aprendizagem. Epistemologia evolutiva e sociedade aberta. Trad. Paula Taipas. Lisboa: Edições 70, 2001.

RESCHER, Nicholas. Presumption and the practices of tentative cognition. Cambridge: Cambridge University Press. 2006.

TARUFFO, Michele. La prueba de los hechos. 3.ed. Trad. Jordi Ferrer Beltrán. Madrid: Trotta, 2009.

TARUFFO, Michele. La simplice verità. Il giudice e la costruzione dei fatti. Roma: Laterza, 2009.

WILD, Rodolfo. A epistemologia do princípio do livre convencimento: reminiscência de um paradigma autoritário de processo no âmbito do novo código de processo civil. São Leopoldo: Universidade do Vale do Rio de Sinos, Programa de Pós-Graduação em Direito, Doutorado, 2016. 